\title{
Microfranchising rural sanitation: a sustainable development model for a scale-up of a sustainable technology
}

\author{
S. Mecca ${ }^{1}$, H. Davis ${ }^{2} \&$ A. Davis ${ }^{3}$ \\ ${ }^{1} S$-Lab, Department of Engineering-Physics-Systems, \\ Providence College, USA \\ ${ }^{2}$ New York University, Interactive Telecommunications, \\ Tisch School, USA \\ ${ }^{3}$ Cooper Union, Albert Nerken School of Engineering, USA
}

\begin{abstract}
The GSAP Microflush toilet system, a locally sourced-locally fabricated toilet that features a macro-organism enhanced aerobic filter-digester and an innovative valve that flushes on just $150 \mathrm{cc}$ of water has proven to be an effective sustainable sanitation solution for developing world tropical communities. This paper examines a sustainable model for bringing the technology to scale by bringing together the building and microfinance functions necessary for the neediest of households to own such a toilet. The plan developed by the non-profit Global Sustainable Aid Project and the S-Lab replaces outright grants with progressive performance based loans to the microfranchise with a model that has appeal for traditional philanthropic and humanitarian aid foundations. The goals and structure of the model and pro forma for alternative scenarios emphasizing the sustainable elements of the approach are described. Early results of the application are presented.

Keywords: rural sanitation, toilets, off-grid, closed systems, open source sanitation, sanitation credit, microcredit, microfranchise, macro-organism enhanced digestion, aerobic digestion, microflush valve.
\end{abstract}

\section{The technology}

Under a Grand Challenges Explorations Award from the Bill \& Melinda Gates Foundation, the Global Sustainable Aid Project (in Ghana known as the Ghana 
Sustainable Aid Project) or GSAP successfully prototyped a marriage of two technologies: a filter-digester and the Microflush valve. The valve, which was designed in the S-Lab in the Department of Engineering-Physics-Systems at Providence College flushes on as little as $150 \mathrm{cc}$ of reused water from the previous user's hand washing and results in an isolation of waste from human contact, eliminating odors and disease-bearing flies. GSAP has incorporated the valve into multiple designs including a generic macro-organism enhanced aerobic digester. The resulting GSAP Microflush (GMF) system has been designed in a model that is fabricated using local skills and local materials.

The technology from the prototype systems to the new locally sourced-locally fabricated model is more fully described in recent papers [1, 2]. A photo of typical stalls is shown in Figure 1. By design, each stall is fitted with a hand wash station, which is either outfitted with a low-flow handle-less faucet aerator with supply from an overhead bucket or, in a simpler inexpensive arrangement with a handled cup to a bowl for handwash and a pour flush.

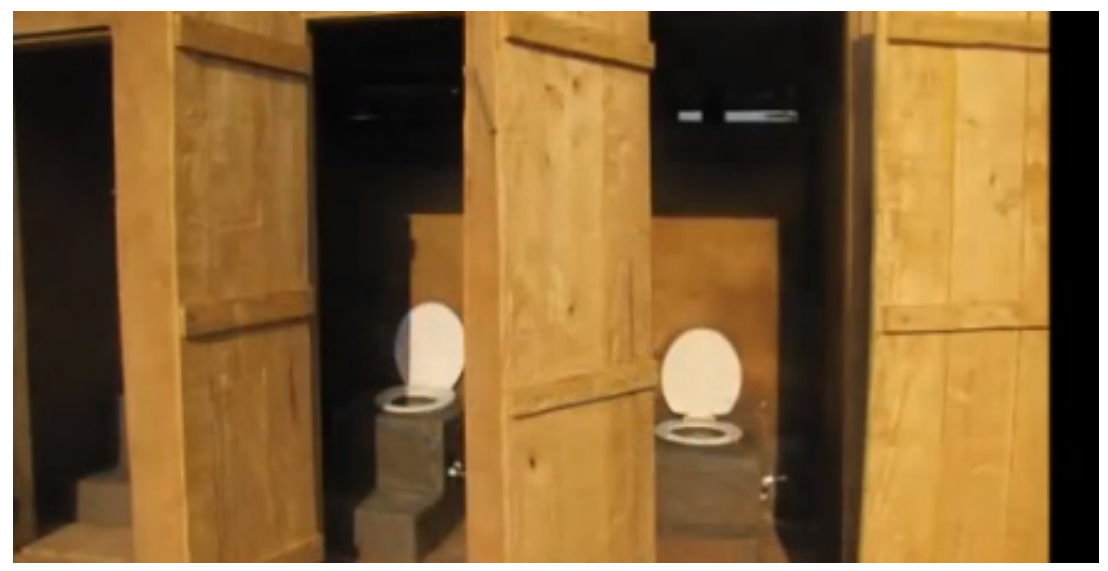

Figure 1: Typical stalls in a GSAP Microflush toilet. (In this case this is part of a school toilet block.)

The grey water from hand washing is used for the ensuing flush of the toilet. When water is present in the pan-type Microflush valve, it provides a separation of waste from space and human contact thus controlling odors and eliminating flies. The waste is directly released to the digester bed which does a rapid separation of liquids from solids. The Microflush system and its material flows are shown in Figures 2(a) and (b) respectively. A little more than $0.5 \mathrm{~kg}$ of input per average use results in less than 15 gms of solids. The liquid filtrate from 15 uses is less than 8 liters. In the prototype systems the filtrate is allowed to penetrate a small sandy leaching field. Current work in our laboratory is exploring four options for removing the pathogens from this relatively small volume of liquids. One of these, SOLDIS treatment [3] will be field tested in 2015 and will hopefully result in the first virtually closed toilet system in the world providing installation options even for the most sensitive swampy areas. 


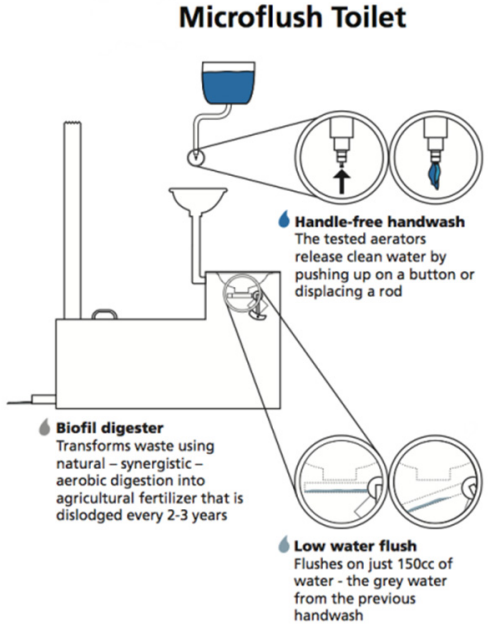

(a)
What goes in:

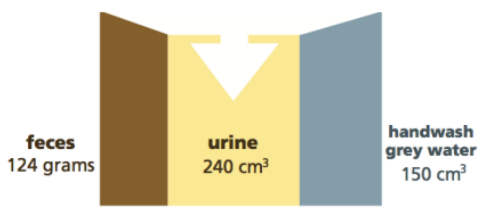

What comes out:

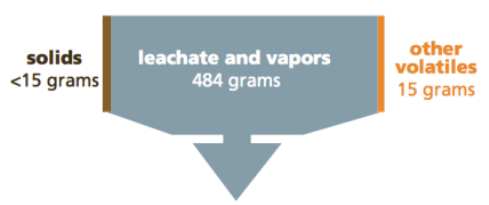

(b)

Figure 2: (a) Overview of the elements and (b) material flows (per user inputs and outputs) of a GSAP Microflush toilet.

\section{Going to scale}

Some 2.5 billion people worldwide lack access to effective sanitation. While sanitation has been part of UN millennium goals $[4,5]$ and while proven technologies such as the GSAP Microflush toilet offer promise from a sustainable technology perspective, there are challenges in bringing the technology to scale. Earlier work [1,2] analyzed two broad models: the central production model (CPM) and the on-site fabrication (OSF) model. GSAP has chosen the latter for two reasons. First, it results in a far more affordable solution and second, it enhances community development. Indeed, recent funding for the CPM approach has enabled a subsidy for factory produced toilets; even with the subsidy, the GSAP OSF model is a factor of 2 less expensive. Including a $\$ 100$ average profit to the MAKER (as GSAP calls the locally trained toilet builder), the price of a GSAP Microflush toilet to a household ( $\sim 3$ families) is just under $\$ 300$ in West Africa and closer to \$200 in Nepal and India. Nevertheless, it is very difficult for a household in the lowest quintile of the household income spectrum to accumulate $\$ 300$ and hence toilet ownership is not possible without access to affordable micro- or sanitationcredit.

The dire need and the seeming impossibility of ownership leads philanthropic individuals, faith-based organizations, service organization foundations, nonprofits and NGOs to raise funds for donating toilets to such households, an admirable but unsustainable approach for solving the problem for 2.5 billion of the world's population. 
In the next section we describe a sustainable alternative to charity in meeting the sanitation needs of rural and per-urban communities around the world.

\section{The GSAP microfranchise model}

Each year hundreds of grants, awarded by individuals and sanitation-minded organizations, are made to effect ownership by or access toilets for needy people in the world. These donations of a few hundred to a few thousand to tens of thousands of dollars or more result in ownership of one to tens to a hundreds or more toilets to households in need. Clearly, we are not going to be able to give toilets to 2.5 billion people. Further, the unconditional gift of a toilet may not be the best way to influence proper toilet maintenance of the toilet; we always tend to take better care of something we have invested our own resources in than something that has been given outright. Yet, studies have documented that the primary reason for households not owning a toilet is a lack of money; Nimoh et al. [6] and references therein provide compelling evidence.

With the advance of the its locally-sourced locally-fabricated model, GSAP began training and certifying toilet MAKERs for the household GSAP Microflush toilet in June 2013, a process that started in Ghana and has since spread to other countries in Africa and beyond. When households pool resources and save or have access to affordable microcredit, the process works well. For countries where an annual interest rate of $20 \%$ and a down payment of $\$ 100$ can be applied, $\$ 10$ per month for 24 months enables ownership. This sum is far less than the accumulated fees that household members would pay for using a public toilet. GSAP has tested the loan model since the days of its prototype installations and there has not been a single default on such a loan. However, there are so many communities where microcredit is not available or where it is not accessible to the poorest households.

GSAP began proposing a microfranchise model nearly 2 years ago [7] Consultation with philanthropists and members of service organizations (e.g. Rotary) and faith-based organizations have resulted in the idea of expanding the MAKER program to include microfinance functions. It involves:

1. The identification of an individual or individuals interested in and committed to establishing a Microflush toilet enterprise with MAKER and finance functions. We call this a Microfranchise Enterprise (MFE).

2. Training in both fabrication and the essential business elements for running the MFE.

3. A series of interest free progressive performance-based loans (PPBL) to the MFE to get it underway.

4. MFE use of the PPBL loans in making microcredit loans for household toilet purchase.

5. MFE retention of a portion of its profits to build its assets.

6. Repayment of the PPBL loans as the MFE is able to use its own assets for making new toilet microloans.

7. Recycling of PPBL loan repayments to create MFEs in other communities. 
An ideal example of the model is depicted in the scenario assumptions and accompanying pro-forma in Figure 3. PPBLs totaling $\$ 9600$, given in amounts of $\$ 600, \$ 1000, \$ 2000, \$ 2000, \$ 2000$ and \$2000 in months 1, 2, 3, 5, 7 and 9 respectively. The initial $\$ 600$ loan enables the MFE to purchase (locally) a MAKER tool set and make loans for 2 household toilets in the first month. Subsequent loans allow microfinancing 5 toilet purchases per month through month 10. Each stage is carefully monitored before the next stage is deployed. Beginning in month 11, the MFE has sufficient assets to make 5 toilet loans each month. Figure 3 shows the MFE's assets and PPBL loan balance going forward. Notice that in this scenario, the MFE's assets never go below $\$ 2000$ and by month 44 it has paid back the original PPBL funds and is free standing. PPBL repayments are available to create another MFE in another community making this approach to both rural sanitation and community development completely sustainable. In the 44 month period, the MFE has provided 217 microloans for household toilet purchases. We call this model the 'ideal' loan/grant as it doesn't rely on the MFE doing business with loan-free outright sales and there is a cushion in its asset development trajectory.

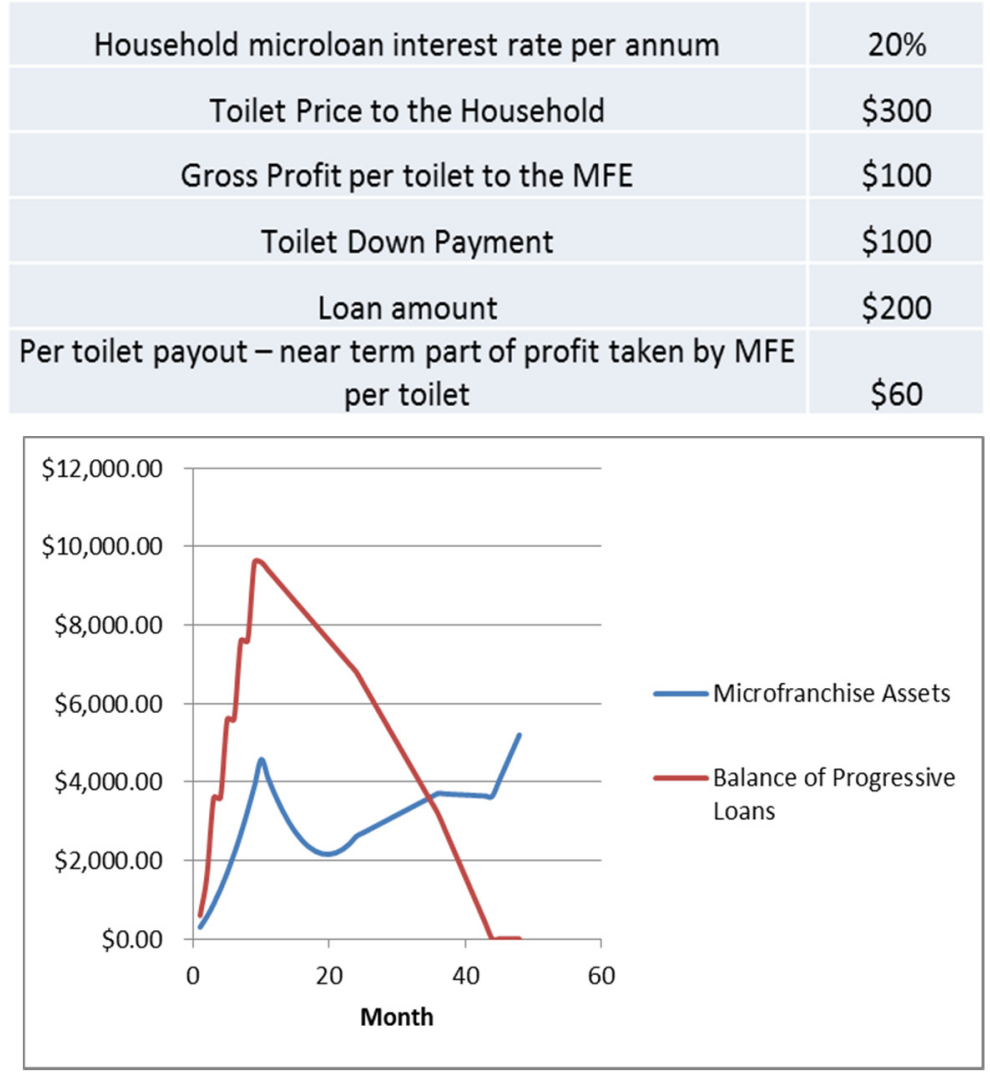

Figure 3: Assumptions and (partial) pro forma for the ideal scenario (see text). 
In bringing the ideal loan/grant scenario to service organizations such as Rotary International, which currently has a water and sanitation focus in its Global and District Grants programs, one has to accommodate the context and limits of such grants. Rotary grants generally close in 2 years. The aforementioned ideal program theoretically never closes. Also, district grants, which are often undertaken by clubs in a Rotary district, are more in the range of $\$ 5000-\$ 6000$. These grants may involve revolving funds but once such grant funds are circulated twice, the grant is expected to be 'closed'. This precludes the possibility of the ideal, never closed concept. To accommodate these constraints, we have developed a lower total-grant program that puts more stress on the MFE in having to secure loan-free sales along with microfinanced toilet sales. Here, a 3 stage PPBL grant/loan totaling \$5400 is made over 3 months and only $\$ 1000$ is considered payable. Month 1 is similar to the ideal PPBL, where the MAKER tool set is purchased and the first 2 household toilets are built and purchased with microloans to the households. In month 2, this model differs from the ideal one. The MFE uses $\$ 4400$ of grant funds; $\$ 4000$ is used to build a 10 stall school toilet block with the school paying $\$ 1000$ of the total cost (or an equivalent number of stalls in more than one school in the community). The school commitment includes: contributing $\$ 600$ in materials and/or labor to the cost of construction plus assurance that a small upper class student team will be put in place to effect daily cleaning of the toilet facilities. The $\$ 1000$ return of loan by the MFE will be used by it to eventually create a water harvesting system(s) at the school(s) and the school must commit to provide 5 scholarships for community girls as its share of the water harvesting system. Month 3 of the PPBL involves $\$ 400$ for the making of 2 more microfinanced household toilets. While this model doesn't perpetuate the creation of MFEs, it does build one sustainable MFE and it is consistent with the context of the aforementioned Rotary grants and with the missions of NGOs that emphasize girls' education and WASH projects at schools. Indeed it is difficult to design a sustainable program for the development of school sanitation facilities so the inclusion of the school block is an attractive feature in this scenario. Figure 4 shows the asset and "loan" balance dynamics for this scenario. The microloan, cost, profit and other parameters are the same as in the ideal scenario. The cost of the 10 stall school toilet block is $\$ 5000$ with a profit of $\$ 1000$ to the MFE. Notice that this model does not enjoy a large asset cushion; the assets come very close to bottoming out in month 14, but the MFE becomes free standing by month 30 when its modest $\$ 1000$ liability is given over to create the school water harvesting project.

Figure 5 shows the school and household toilets projected to be completed by the MFE over the first 24 months of the enterprise. In all some 127 toilets, 117 household systems and one 10-stall school block. Seventy-nine of the household units receive microfinancing and 48 are assumed not to require loans creating some measure of sales stress on the emerging enterprise compared to the 'ideal' scenario where all of the toilets are created with microloans. In one of the countries in which GSAP is working, a system of forced saving for a toilet has 

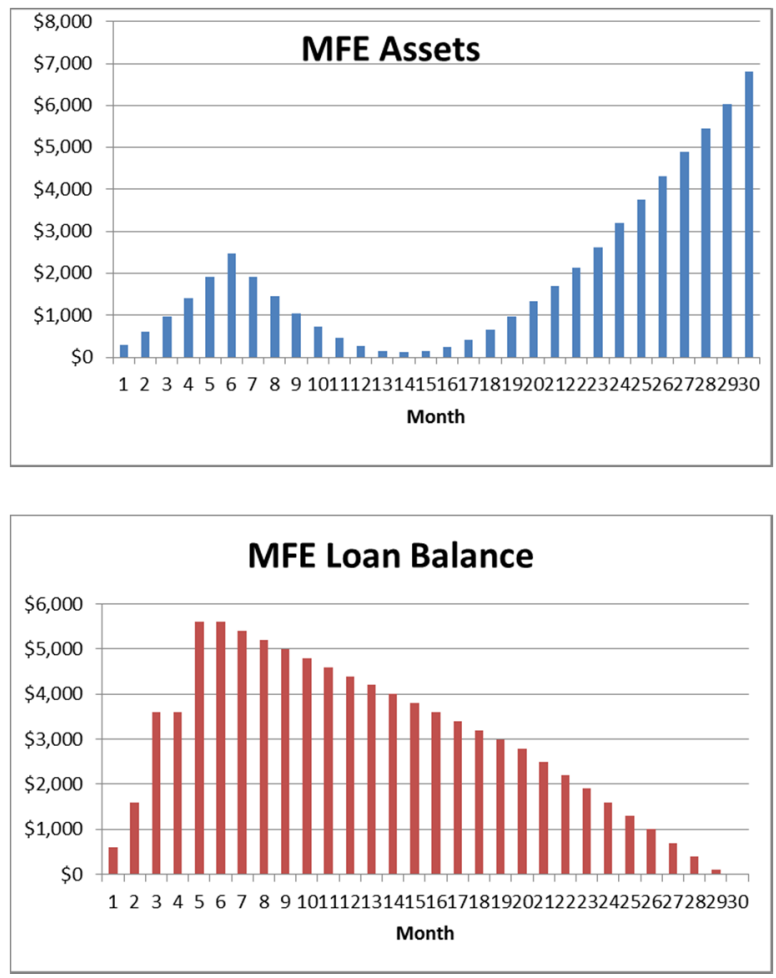

Figure 4: MFE assets and loan balance for a Rotary/District Global Grants model.

been used; it is akin to the 'lay away' plan that US retailers have used for large ticket purchases. Nevertheless, for households in the lowest two quintiles of the household income spectrum, i.e. $\$ 700$ to $\$ 1200$ per annum earnings, saving is extremely challenging and the availability of sanitation credit is the only way to effect toilet ownership. It is interesting that the historical default rate for GSAP provided 'test' loans such as those profiled in this section is virtually zero. So, given the overwhelming acceptance of the GSAP Microflush toilet, the sanitation credit arrangement has the potential to move the technology to scale given sufficient access to PPBL grant/loan capital. Neither of the aforementioned pro formas include the benefits of the harvested compost to the MFE or the toilet owner or both nor do they include downstream revenue to the MFE for the periodic removal service or the revenue from an occasional repair. While not included in the PPBL models, the harvesting services (assuming the benefits of the compost will accrue to the toilet owner) offer the potential of $\$ 10$ to $\$ 30$ revenue to the MFE per toilet stall per 2.5 years (depending on the number of services that the MFE organizes in a service day). Repair service income is difficult to determine but, based on the experience of the period from our prototypes to present, there may be approximately 1 repair per 9 installed toilets 
every 4 years with an average of $\$ 20$ in service per repair. Additional income to the MFE can come from facility upgrade, where for example a household might add interior tile or change the facility enclosure from a frame with $T \& G$ to a masonry structure as it is able to afford this. None of these sources are included in the PPBL-based business models but these surely enhance the sustainability of the enterprise.

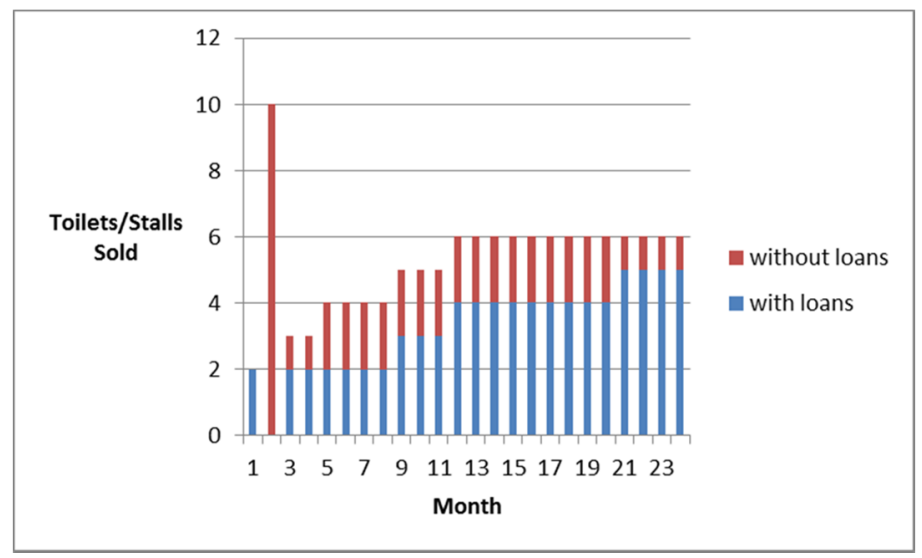

Figure 5: Distribution of the toilets sold with and without microloans in the Rotary District/Global Grants Model.

\section{Conclusion}

We have presented two sustainable models for moving the GSAP Microflush locally sourced locally fabricated toilets to scale. The toilet is an off-grid, sustainable technology that offers an effective solution to peri-urban and rural sanitation in warm climate communities in the developing world. The models build upon the success to date of the MAKER program of the Global Sustainable Aid Project, which has already trained toilet MAKERs in 11 countries around the globe. In moving forward it has begun partnerships with sanitation-minded organizations to deploy microfranchise models that couple MAKER and sanitation (micro)credit functions to effect profitable and sustainable business enterprises focused on improving the condition of sanitation in the communities they serve.

Two MFE models have been outlined each involving a series of progressive performance based loans/grants, one totaling $\$ 9600$ and another $\$ 5400$. Between the ideal $\$ 9600$ and $\$ 5400$ PPBL's is a continuum that can fit philanthropic guidelines in ways that depend on the desired rate of progress towards a free-standing MFE, the scale of desired sustainability and the constraints of the grantor. The programs outlined resonate with GSAPs belief that by improving the condition of sanitation in a community you also improve educational opportunity (especially the education of girls), morbidity and mortality, community and country development and basic human dignity [8]. 


\section{Acknowledgement}

The authors are members of the Global Sustainable Aid Project (GSAP), globalsustainableaidproject.org.

\section{References}

[1] Mecca, S., Davis, H. \& Davis, A., The Microflush/Biofil System: Results to Date of Prototype Installations in Ghana, Fecal Sludge Management FSM2 Conference, Durban 2012.

[2] Mecca, S., Davis, H. \& Davis, A., Application of GSAP Microflush toilets: a sustainable development approach to rural and peri-urban sanitation, WIT Transactions Ecology and the Environment, Vol. 175 WIT Press, UK, 2013.

[3] Mecca, S., Pellock, B., Bretz, R., Pathogen removal options emphasizing SOLDIS for the filtrate of a GSAP Microflush toilet, WIT Transactions on Ecology and the Environment, Vol. 178 WIT Press, UK, 2013.

[4] The Millennium Development Goals Report 2009. New York: United Nations.

[5] Progress on drinking water and sanitation, Joint Monitoring Programme update 2014, WHO/UNICEF Joint Monitoring Programme for Water Supply and Sanitation.

[6] Nimoh, F., Poku, K., Ohene, K, Konrdsen, F., Abaidoo, R., Households' Latrine Preference and Financing Mechanisms in Peri-urban Ghana, Journal of Economics and Sustainable Development, Vol. 5, No. 16, 2014.

[7] Mecca, S., An Open-Source Model for Scaling Up the GSAP Microflush Toilet, Global Health and Innovation, New Haven, CT. April, 2013.

[8] Mecca, S., Davis, H. \& Davis, A., Observing how 'system unto system runs': WATSAN, Dignity, Health, Education and Opportunity, WIT Transactions on Ecology and the Environment, Vol. 153 WIT Press, UK, 2011. 